\title{
Study of BISAP Scoring System, Ranson's Scoring System and C-Reactive Protein Level as Predictors of Clinical Outcome in Acute Pancreatitis
}

\author{
Gaikwad Avinash Machindra ${ }^{1}$, K.V. Rajeshwara ${ }^{2}$ \\ ${ }^{1}$ Department of General Surgery, Dr. Shankarrao Chavan Govt Medical College, \\ Vishnupuri, Nanded, Maharashtra, India. ${ }^{2}$ Department of General Surgery, Father Muller \\ Medical College, Kankanady, Mangalore, Karnataka, India.
}

\section{ABSTRACT}

\section{BACKGROUND}

This study was conducted to compare BISAP scoring system, Ranson's score and CRP levels in predicting the clinical outcome in acute pancreatitis and for early detection of severity and organ failure in acute pancreatitis.

\section{METHODS}

This study was an observational longitudinal analytical study conducted among patients admitted with diagnosis of acute pancreatitis, in Father Muller Medical College Hospital, Mangalore, from November 2016 to March 2018. The study was started after obtaining ethical clearance from the institution's ethical clearance committee. All patients diagnosed with acute pancreatitis between the age 20 and 60 years were included in the study.

\section{RESULTS}

Comparison of serum CRP levels between the Atlanta classified groups shows that severe group has the maximum value of 340.966 and mild has the minimum value of 55.38. This difference is statistically significant with a test value of 16.543 and a $P$ value of $<0.001$. On comparison of the test group, Ranson's score with the BISAP score, the test group had a sensitivity of $89.3 \%$ and specificity of $77.3 \%$.

\section{CONCLUSIONS}

The study has demonstrated the concordance between Ranson's score, BISAP score and serum CRP level as predictors of clinical outcome in acute pancreatitis.

\section{KEY WORDS}

Acute Pancreatitis, Clinical Outcome, C Reactive Protein, Scoring Systems.
Corresponding Author: Dr. K.V. Rajeshwara, Associate Professor, Department of General Surgery, Father Muller Medical College,

Kankanady, Mangalore - 575002,

Karnataka, India.

E-mail: rajeshwarakv@gmail.com

DOI: $10.14260 / \mathrm{jemds} / 2021 / 168$

How to Cite This Article: Machindra GA, Rajeshwara KV. Study of bisap scoring system, ransons scoring system and C-reactive protein level as predictors of clinical outcome in acute pancreatitis. J Evolution Med Dent Sci 2021;10(11):784-788, DOI: 10.14260/jemds/2021/168

Submission 20-10-2020,

Peer Review 22-01-2021,

Acceptance 28-01-2021,

Published 15-03-2021.

Copyright (C) 2021 Gaikwad Avinash Machindra et al. This is an open access article distributed under Creative Commons Attribution License [Attribution 4.0 International (CC BY 4.0)] 


\section{BACKGROUND}

Acute pancreatitis is one of the common and potentially lethal conditions. Acute pancreatitis is one of the commonest acute abdominal disorders necessitating emergency admission. Acute pancreatitis is inflammation of pancreatic parenchyma with involvement of peripancreatic tissue and associated multi-organ involvement due to the release of inflammatory mediators. This can lead to potentially distressing consequences ${ }^{1}$. Most cases of acute pancreatitis are mild and self-limiting. $20-30 \%$ of the cases will have a rapidly progressive inflammatory response with significant complications. Severe pancreatitis patients end up with mortality of 10 - $30 \% .1,2,3$

In acute pancreatitis, it is important to identify the patients who will develop severe form, as they are with poor prognosis. They can be treated aggressively to improve the outcome and survival.

To assess the severity of the disease, various types of scoring systems have been proposed and introduced since 1974. An ideal scoring system should be easy, perfect and should forecast the severity of the disease at any time. The scoring systems which are available and in practice are not suitable for predicting the severity of acute pancreatitis.

There are several prognostic indicators developed for forecasting clinical outcome in acute pancreatitis like Ranson's, modified Glasgow, MOSS, CT severity index, APACHE II scoring systems and biochemical markers like CRP, IL 6 and serum prolactin level.4,5

Recently, BISAP scoring system and C-reactive protein (CRP) level are developed for prediction of clinical outcome in acute pancreatitis. 6,7 BISAP score has fewer items to measure which are cost effective and can be assessed even in an emergency setting.

Major disadvantage of Ranson's criteria is that it does not give the clear picture of the severity at the time of admission because six out of total eleven parameters are assessed only after 48 hours. This can lead to increase in the mortality due to delay in the aggressive intervention.1,8 Although the Acute Physiology and Chronic Health Evaluation (Apache)-II scoring system can be used on admission and can be repeated at any time, the complexity of the parameters may not be specific for acute pancreatitis.1,9 Using imaging characteristics CTSI (computed tomographic severity index) is calculated based on local complications like fluid collection, phlegmon or necrosis and which cannot be correlated to systemic inflammatory response. 1,10

\section{BISAP Scoring System}

A prognostic scoring system - Bedside Index for Severity in Acute Pancreatitis (BISAP) has been proposed by, Wu et al.11 to identify the patients who are at risk for in-hospital mortality.

Components of bedside index for severity in acute pancreatitis (BISAP) score -

- $\quad$ Blood urea nitrogen $(B U N)>25 \mathrm{mg} / \mathrm{dl}$. $(8.9 \mathrm{mmol} / \mathrm{L})$ 1 point.

- Impaired / abnormal mental status (Glasgow Coma Score $(\mathrm{GCS})<15)-1$ point
- Evidence of systemic inflammatory response syndrome (SIRS) is defined as two or more of following. - 1 point.

- Temperature of $\left(<36^{\circ} \mathrm{c}\right.$ or $\left.>38^{\circ} \mathrm{c}\right)$.

- Respiratory rate $>20 / \mathrm{min}$ or $\mathrm{PaCo} 2<32 \mathrm{~mm} \mathrm{hg}$.

- Pulse $>90 / \mathrm{min}$.

- $\mathrm{WBC}<4,000$ or $>12,000$ cells $/ \mathrm{mm}^{3}$ or $>10 \%$ immature bands.

- $\quad$ Patient age $>60$ years. -1 point

- Imaging study reveals pleural effusion. - 1 point

Points given for each variable and score calculated within 24 hours of diagnosis.

A score $>3$ indicates severe acute pancreatitis with increased morbidity and mortality.

\section{Ranson's Criteria}

The criteria are named after Dr. John Ranson who introduced them in his article "Prognostic signs and the role of operative management in acute pancreatitis" which was published during the year 1974. Total eleven objective findings were determined for predicting severity of AP. Five criteria will define and measure the severity of inflammatory process on admission. Other six criteria will identify the effect of circulating enzymes and toxins in circulation after 48 hours. ${ }^{12}$ The score of 3 or more criteria signifies severe pancreatitis.

\begin{tabular}{|cc|}
\hline At Admission & During Initial 48 Hrs. \\
Non-gallstone pancreatitis: & Decrease in haematocrit $>10 \%$ \\
Age $>55$ years & Blood urea nitrogen: increase $>5 \mathrm{mg} / \mathrm{dl}$ \\
$\mathrm{WBC}$ count $>16,000 \mathrm{cells} / \mathrm{mm}^{3}$ & Serum calcium level $<8 \mathrm{mg} / \mathrm{dl}$ \\
Blood glucose $>200 \mathrm{mg} / \mathrm{dl}$ & Arterial $\mathrm{PaO}_{2}<60 \mathrm{~mm} \mathrm{Hg}$ \\
Lactate dehydrogenase $>350 \mathrm{IU} / \mathrm{Liter}$ & Base deficit $>4 \mathrm{mmol} / \mathrm{L}$ \\
$\begin{array}{c}\text { Aspartate aminotransferase }>250 \mathrm{IU} / \\
\text { Liter }\end{array}$ & Fluid requirement $>6$ Liters \\
\hline Table 1. Ranson's Criteria in Alcohol Induced \\
and Other Acute Pancreatitis
\end{tabular}

\begin{tabular}{|cc|}
\hline At Admission & During Initial 48 Hrs. \\
Age $>70$ years & Decrease in PCV $>10$ points \\
WBC count $>18,000$ cells $/ \mathrm{mm}^{3}$ & Increase in $\mathrm{BUN}>2 \mathrm{mg} / \mathrm{dl}$ \\
Blood glucose $>220 \mathrm{mg} / \mathrm{dl}$ & Serum calcium level $<8 \mathrm{mg} / \mathrm{dl}$ \\
Lactate dehydrogenase $>400 \mathrm{IU} /$ Liter & Base deficit $>5 \mathrm{mmol} / \mathrm{Liter}$ \\
Aspartate aminotransferase $>250 \mathrm{IU} / \mathrm{Liter}$ & Fluid requirement $>4 \mathrm{Litres}$ \\
\hline Table 2. Ranson's Criteria in Acute Gallstone Pancreatitis \\
\hline
\end{tabular}

\section{C-Reactive Protein (CRP) ${ }^{12}$}

CRP an acute phase protein synthesised by hepatocytes induced by cytokines as a result of acute inflammation. Significant rise in CRP levels indicates inflammation. The CRP concentration increases with progressive inflammation and decreases fast because of its shorter half-life. The level can go up to $50-100 \mathrm{mg} / \mathrm{L}$ in mild pancreatitis but level of more than $150 \mathrm{mg} / \mathrm{L}$ suggests severe pancreatitis. As the estimation of CRP cannot be done at admission, the sensitivity of the assay decreases. Other biochemical markers like serum procalcitonin, IL - 6. IL - 1 elastase can be used as predictor of severity. But the cost of these markers make CRP estimation, a better alternative, as it is cheap and widely available.

In view of the above factors, this study was conducted to know the comparison between BISAP scoring system, Ranson's score and CRP level in predicting the clinical outcome in acute pancreatitis. 
This study was conducted to assess the usefulness of BISAP and Ranson scoring system and CRP level in predicting the severity and organ failure in acute pancreatitis.

\section{METHODS}

This study was an observational longitudinal analytical study performed on patients admitted with diagnosis of acute pancreatitis in Father Muller Medical College Hospital, Mangalore from November 2016 to March 2018 on those who met a pre-defined criterion. The study was started after obtaining necessary ethical clearance from the institution's ethical clearance committee. All patients admitted with pain abdomen and diagnosed with acute pancreatitis by clinical examination and further investigations in Father Muller Medical College Hospital, Mangalore were included in the study. All patients diagnosed with acute pancreatitis between age group of 20 to 60 years including pancreatitis caused by medications were included in the study. After obtaining written informed consent, 94 patients diagnosed to have acute pancreatitis in accordance with revised Atlanta 2012 definition were included in study and classified in to mild or severe pancreatitis.

\section{Exclusion Criteria}

- Patients with comorbidities like diabetes mellitus (DM), Hypertension (HTN), Asthma etc.

- $\quad$ Patients with chronic pancreatitis.

\section{Sample Size Estimation}

Sample size 94 was included in the study at $95 \%$ confidence interval and $10 \%$ allowable error based on the article ${ }^{13}$ wherein elevated CRP level in acute pancreatitis was quoted as $\mathrm{P}=46 \%$ and calculated based on the formula

$$
\mathrm{n}=\frac{\mathrm{z}_{\alpha} 2 \mathrm{p}(1-\mathrm{p})}{\mathrm{e} 2}
$$

\section{Statistical Analysis}

Based on the findings and data, patients were divided into mild pancreatitis, moderately severe pancreatitis and severe pancreatitis as per the Atlanta definition criteria. Collected data was summarised by frequency, percentage, mean and standard deviation. To ascertain significance, to compare and to find the difference chi-square test was performed. To find the diagnostic accuracy, sensitivity, specificity, positive predictive value and kappa statistics were calculated. Analysis of variance (ANOVA) test was performed to compare the mean between the several groups followed by Tukey post-hoc test. Level of significance was $5 \%$ and analysis was performed using Statistical Package for the Social Sciences (SPSS)-23 software.

\section{RESULTS}

Comparison of serum CRP levels between the Atlanta classified groups showed that severe group had the maximum value of 340.96 and mild variety had the minimum value of 55.38. This variance is statistically significant with a test value of $16.543^{*}$ and P-value of $<0.001$. Tukey post-hoc test comparing mild and moderately severe groups showed a mean difference of - 135.26 and was statistically substantial with a P-value of 0.001. Comparing mild and severe groups expressed a mean difference of - 285.58 and was statistically noteworthy with a P-value of $<0.001$. Comparing moderately severe and severe groups displayed a mean difference of - 150.32 and was statistically important with a P-value of 0.009.

\begin{tabular}{|cccccc|r|}
\hline & Type & No & CRP Value & SD & P-Value \\
& Mild & 44 & 55.38 & 78.48 & & \\
Serum CRP & Moderately severe & 35 & 190.64 & 150.98 & $16.543^{*}<0.001$ \\
& Severe & 15 & 340.96 & 306.86 & & \\
& Total & 94 & 151.32 & 189.98 & & \\
\hline \multicolumn{5}{|c|}{ Table 3. Serum CRP Level in Different Types of AP } & \\
\hline
\end{tabular}

\section{BISAP Score Pancreatitis}

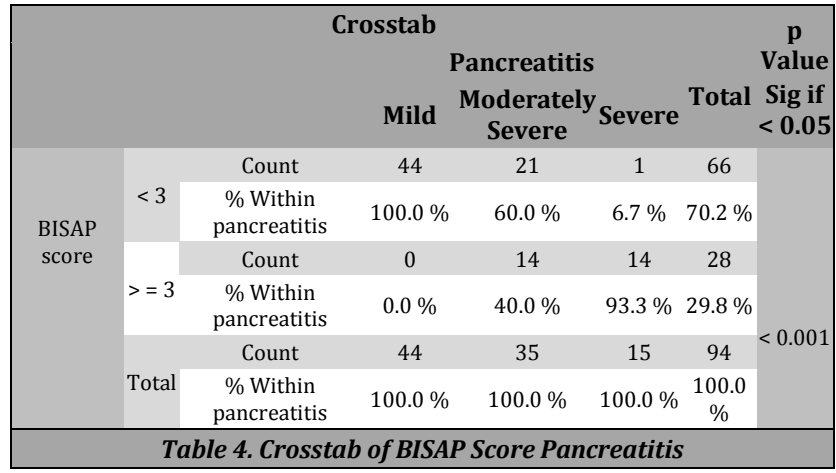

Compared to BISAP group scores with the typical type of pancreatitis the experimental group showed $56 \%$ sensitivity and $100 \%$ specificity. The test has valid guess value of $100 \%$ and an unpredictable value of $66.7 \%$. The test with a gold standard corresponds to 72 out of 94 indicating accuracy of $76.59 \%$. The kappa value of 0.544 specifies a good agreement with a P-value of $<0.001$.

\section{Ranson's Score Pancreatitis}

\begin{tabular}{|c|c|c|c|c|c|c|c|}
\hline & & & Crosstab & & & & p \\
\hline & & & & Pancreatitis & & & Value \\
\hline & & & Mild & $\begin{array}{l}\text { Moderately } \\
\text { Severe }\end{array}$ & Severe & Total & $\begin{array}{l}\text { Sig if } \\
<0.05\end{array}$ \\
\hline & & Count & 39 & 15 & 0 & 54 & \\
\hline Ranson's & $<3$ & $\begin{array}{c}\text { \% Within } \\
\text { pancreatitis }\end{array}$ & $88.6 \%$ & $42.9 \%$ & $0.0 \%$ & $57.4 \%$ & \\
\hline score & & Count & 5 & 20 & 15 & 40 & \\
\hline & $>=3$ & $\begin{array}{c}\% \text { Within } \\
\text { pancreatitis }\end{array}$ & $11.4 \%$ & $57.1 \%$ & $100.0 \%$ & $42.6 \%$ & \\
\hline & & Count & 44 & 35 & 15 & 94 & $<0.001$ \\
\hline & Total & $\begin{array}{c}\% \text { Within } \\
\text { pancreatitis }\end{array}$ & $100.0 \%$ & $100.0 \%$ & $100.0 \%$ & $100.0 \%$ & \\
\hline
\end{tabular}

Compared to Ranson's group scores with the typical type of pancreatitis, the experimental group showed $70 \%$ sensitivity and $88.6 \%$ specificity. The test had valid guess value of $87.5 \%$ and an unpredictable value of $72.2 \%$. The test with a benchmark corresponded to 74 out of 94 indicating 
accuracy of $78.72 \%$. The kappa value of 0.578 specifies a good agreement with a P-value of $<0.001$.

\section{Modified Marshall Score Pancreatitis}

\begin{tabular}{|c|c|c|c|c|c|c|c|}
\hline & & & Crosst & & & & $\mathbf{P}$ \\
\hline & & & & Pancreatitis & & & Value \\
\hline & & & Mild & $\begin{array}{c}\text { Moderately } \\
\text { Severe }\end{array}$ & Severe & Total & $\begin{array}{c}\text { Sig if }< \\
0.05\end{array}$ \\
\hline & & Count & 44 & 30 & 2 & 76 & \\
\hline Modified & $<3$ & $\begin{array}{c}\% \text { within } \\
\text { pancreatitis }\end{array}$ & $100.0 \%$ & $85.7 \%$ & $13.3 \%$ & $80.9 \%$ & \\
\hline $\begin{array}{l}\text { Marshall } \\
\text { score }\end{array}$ & & Count & 0 & 5 & 13 & 18 & \\
\hline & $>=3$ & $\begin{array}{c}\% \text { within } \\
\text { pancreatitis }\end{array}$ & $0.0 \%$ & $14.3 \%$ & $86.7 \%$ & $19.1 \%$ & \\
\hline & & Count & 44 & 35 & 15 & 94 & $<0.001$ \\
\hline & Total & $\begin{array}{c}\% \text { within } \\
\text { pancreatitis }\end{array}$ & $100.0 \%$ & $100.0 \%$ & $100.0 \%$ & $100.0 \%$ & \\
\hline
\end{tabular}

On comparison of Modified Marshall Score, study group with the typical type of pancreatitis had $36 \%$ sensitivity and $100 \%$ specificity. The test had a fairly estimated value of 100 $\%$ and an unpredictable guess value of $57.9 \%$. The test value of gold standard corresponds to 62 out of 94 with an impressive accuracy of $65.95 \%$. Kappa value of 0.345 specifies the estimated value and $\mathrm{P}$ of $<0.001$.

\section{DISCUSSION}

\section{Type of Pancreatitis and BISAP Score}

Comparing the BISAP group scores with the type of pancreatitis, the experimental group had $56 \%$ sensitivity and $100 \%$ clarity. The test had a fairly estimated value of $100 \%$ and a negative prediction value of $66.7 \%$. Test and gold standard ratings were 72 out of 94 with a diagnostic accuracy of $76.6 \%$. Kappa value of 0.544 indicates a positive agreement with a $\mathrm{P}$ value of $<0.001$

\section{Type of Pancreatitis and Ranson's Score}

Comparing the Ranson's group scores with the type of pancreatitis the experimental group had a sensitivity of $70 \%$ and a specificity of $88.6 \%$. The test has a good guessing value of $87.5 \%$ and an unpredictable value of $72.2 \% .{ }^{14}$ The average gold standard was 74 out of 94 with a diagnostic accuracy of $78.72 \%$. Kappa value of 0.578 indicates a positive agreement with a $\mathrm{P}$ value of $<0.001$.

\section{Comparison of Ranson's Score and BISAP Score} Compared to the Ranson's score and BISAP group the test group had a sensitivity of $89.3 \%$ and a specificity of $77.3 \%$. The trial group had a fairly estimated value of $62.5 \%$ and an unpredictable estimate value of $94.4 \%$. The trial and gold standard group agree on 76 out of 94 with a diagnostic accuracy of $80.85 \%$. Kappa value of 0.592 specifies a positive agreement with a P-value of $<0.001$.

\section{CONCLUSIONS}

The study has demonstrated the concordance between Ranson's Score, BISAP score and serum CRP level as predictors of clinical outcome in acute pancreatitis. This concordance shows that prediction of severity and organ failure can be done at the time of admission with the BISAP score and CRP level instead of Ranson's score, which takes 48 hours to be determined. BISAP score and CRP level can be used to determine the severity of organ failure with an equal efficacy to that of Ranson's score.

\section{Limitations of Our Study}

The patients who were included in this study with acute pancreatitis were with either initial attack or relapse of AP. So, the difference between the initial attack and the relapse could not be distinguished.

Data sharing statement provided by the authors is available with the full text of this article at jemds.com.

Financial or other competing interests: None.

Disclosure forms provided by the authors are available with the full text of this article at jemds.com.

\section{REFERENCES}

[1] Hariprasad TR, Haridarshan SJ, Puneetha K, et al. Bisap score: a simple tool to assess the severity and predict the morbidity and mortality in acute pancreatitis. Journal of Evolution of Medical and Dental Sciences 2015;4(101):16642-45.

[2] Jacobs ML, Daggett WM, Civette JM, et al. Acute pancreatitis: analysis of factors influencing survival. Ann Surg 1977;185(1):43-51.

[3] Banks PA, Bollen TL, Dervenis C, et al. Classification of acute pancreatitis--2012: revision of the Atlanta classification and definitions by international consensus. Gut 2013;62(1):102-11.

[4] Kandasamy S. Is it all clear if procalcitonin clears in acute pancreatitis? Indian J Crit Care Med 2020;24(3):149-50.

[5] Choudhuri AH, Duggal S, Biswas PS, et al. A comparison of acute physiology and chronic health evaluation II score and serum procalcitonin change for predicting mortality in acute pancreatitis. Indian J Crit Care Med 2020;24(3):190-4.

[6] Arif A, Jaleel F, Rashid K. Accuracy of BISAP score in prediction of severe acute pancreatitis. Pak J Med Sci 2019;35(4):1008-12.

[7] Papachristou GI, Muddana V, Yadav D, et al. Comparison of BISAP, Ranson's, APACHE-II and CTSI scores in predicting organ failure, complications and mortality in acute pancreatitis. Am J Gastroenterol 2010;105(2):43542.

[8] Shabbir S, Jamal S, Khaliq T, et al. Comparison of BISAP score with Ranson's score in determining the severity of acute pancreatitis. J Coll Physicians Surg Pak 2015;25(5):328-31.

[9] Gooptu S, Singh G, Pithwa AK, et al. Role of scoring systems in acute pancreatitis. Med J DY Patil Univ 2016;9(1):72-8. 
[10] Sahu B, Abbey P, Anand R, et al. Severity assessment of acute pancreatitis using CT severity index and modified CT severity index: correlation with clinical outcomes and severity grading as per the revised Atlanta classification. Indian J Radiol Imaging 2017;27(2):152-60.

[11] Wu BU. Prognosis in acute pancreatitis. CMAJ 2011;183(6):673-7.

[12] Matull WR, Pereira SP, O'Donohue JW. Biochemical markers of acute pancreatitis. J Clin Pathol 2006;59(4):340-4.
[13] Maharaul HH, Dhorajia D. A single institute study of clinical profile of acute pancreatitis. Indian J Appl Res 2015;5:700-2.

[14] Khanna AK, Meher S, Prakash S, et al. Comparison of Ranson, Glasgow, MOSS, SIRS, BISAP, APACHE-II, CTSI scores, IL-6, CRP and procalcitonin in predicting severity, organ failure, pancreatic necrosis and mortality in acute pancreatitis. HPB Surg 2013;2013:367581. 